\title{
The effect of aging on Arenga pinnata fiber-reinforced epoxy composite.
}

\begin{abstract}
This study investigates the effect of aging in Arenga pinnata fiber-reinforced epoxy composites (APFREC) after an accelerated aging process. The APFREC samples composed of $10 \%$ long random fiber by weight were produced by a hand layup process. The tensile and impact tests were performed on the original and aged APFREC to characterize the mechanical properties. The original and aged samples were compared to determine the effects of aging. The results show that aged specimens have higher tensile strength compared to the original specimens, by $50.4 \%$. However for impact tests, the aged specimens show a slight, $6.33 \%$, degradation in impact strength compared to the original specimens. These results show that as the APFREC ages, the composite shows increased ductility but a significant decrease in strength.
\end{abstract}

Keyword: Accelerated aging; Arenga pinnata fiber; Hand lay-up; Impact test; Random fibers; Reinforced epoxy. 